\title{
Examination of Dust Concentration in the Interior Air of a Teaching Room
}

\author{
Halina Marczak ${ }^{1}$ \\ 1 Institute of Transport, Internal Combustion Engines and Ecology, Lublin University of Technology, \\ Nadbystrzycka 36, 20-618 Lublin, Poland, e-mail: h.marczak@pollub.pl
}

\begin{abstract}
The issue of indoor air quality is becoming increasingly important. Ensuring optimal air parameters is important for the health of people who are particularly sensitive to impurities contained therein. Finding solutions that improve the quality of indoor air requires a prior detailed recognition of the problem of its pollution. The subject of the research is dust pollution in the air in a teaching laboratory room. The attention was focused on the characteristics of air pollution with the total dust fraction and suspended particulate fractions PM10 and PM2.5. The dust content was measured with a laser meter enabling indirect measurement. It consists in using the phenomenon of damping laser light scattered on the tested air sample at an angle of 90 degrees. As a result of the conducted research, factors influencing the increase of dust concentration in the indoor air were identified. These include the quality of the outdoor air and the source of dust emission in the room. In order to obtain more comprehensive data, it is necessary to continue the research with the possibility of extending the duration of the measurement tests and the test cycle.
\end{abstract}

Keywords: dust pollution, PM10, respirable fraction, suspended dust fractions, dust concentration in the interior air

\section{INTRODUCTION}

Air quality has a direct impact on human health. Poor air quality can cause adverse health effects, especially respiratory and circulatory system diseases. The respiratory system is one of the basic ways of transferring pollutants to the human body.

Dust is one of the pollutants in the air. The harmfulness of dust to the human body depends on its concentration, grain size (the smaller, the more harmful), shape (circular dust is less harmful), chemical composition, crystalline structure, dust solubility in body fluids and time of impact. Dust contamination, depending on its type, can cause irritating, fibrotic effects (hyperplasia of the fibrous tissue in the lungs), sensitizing or toxic reactions. In people with bronchial asthma, exposure to dust pollution may increase the severity of asthma attacks. The respirable fraction of the dust shows the ability to pass through the alveolar walls, then into the pulmonary blood vessels, and then into the entire human blood system. As a consequence, it can affect the development of atherosclerosis and related cardiovascular diseases.

The article presents the results of dust concentration measurements in a teaching room. The main goal of the research is to obtain data and information on air pollution in teaching rooms and determine whether chalk dust is a factor significantly affecting the quality of indoor air.

\section{CHALK DUST AS AN AIR POLLUTANT}

The exact explanation of the term dust and the definition of the dust fraction are included in Polish standards regarding air quality [PN-ISO 4225:1999, PN-ISO 7708:2001]. The inhalable fraction and the respirable fraction of dust are also explained in the Regulation of the Minister of Labor and Social Policy on the highest permissible concentrations and intensities of harmful factors in the work environment [Announcement 
Dz.U.2017, poz. 1348]. The inhalable fraction is the aerosol fraction penetrating the nose and mouth, which poses a health risk when deposited in the airways. The definition of the inhalable fraction corresponds to the definition of total dust. The respirable fraction is the aerosol fraction entering the respiratory tract, which poses a risk when deposited in the gas exchange area.

Among the harmful dust factors in the work environment which are mentioned in the Regulation, there is a factor: other non-toxic industrial dusts - including those containing free silica below $2 \%$. This category of dusts includes chalk dust. It is included in the group of harmful factors, because it can be irritant or allergic to people. Most often, it has irritating effects on the conjunctiva of the eyes, mucous membranes of the upper respiratory tract and throat. The most harmful to health are fine particles of dust, because they have the ability to penetrate and settle in the area of gas exchange. Dusts with aerodynamic diameters of up to $5 \mu \mathrm{m}$ (respirable fraction) reach the alveoli [Jakubowski 2018]. They can cause pulmonary disease, including bronchial asthma, when located in the lungs. On the other hand, dust particles with aerodynamic diameters above $5 \mu \mathrm{m}$ (unresponsible fraction) are retained in the upper respiratory tract or in the tracheobronchial area, from where they are removed with the participation of ciliated and mucus-secreting epithelial cells. Inhaled dust can sometimes interfere with the ability of the respiratory system to remove dust particles, which may be the cause of chronic bronchitis.

Chalk dust may be an air pollutant inside the teaching rooms. The source of emission of this dust is abrasion, especially dry sponge or chalk from the blackboard. Chalk dust belongs to nontoxic dust due to the chemical composition of the chalk. It is a mixture of chalk and gypsum. Writing chalk is a variation of fairly clean limestone. It consists predominantly of calcium carbonate in a form of calcite. The composition of the masswriting chalk according to Olszewski [1998] is as follows: over $92 \% \mathrm{CaCO}_{3}$, from 4 to $5 \%$ silica, about $2 \%$ clay minerals, about $0.8 \%$ other mineral admixtures.

The basic quantitative measure of atmospheric and internal air dustiness (in work rooms and other places) is the dust concentration (S), which is the ratio of the mass or volume of dust particles to the volume or less often the air mass:

$$
S=\frac{\text { amount of dust (mass or volume) }}{\text { amount of air (mass or volume) }}
$$

On the basis of the dust concentration in the test air, the risk to human health of dust can be assessed.

\section{RESEARCH SUBJECT AND METHODOLOGY}

The subject of the research is dust pollution in the air in a laboratory room. The room has an area of about $30 \mathrm{~m}^{2}$, it is equipped with gravity ventilation and an exhaust fan turned on periodically as needed, most often when working with chemical reagents. The classroom holds classes for groups of students up to 15 people. The duration of one type of class for each group is 2 teaching hours. During the day, classes in the room are carried out for a maximum of 4 groups.

The research included measurements of total (general) dust and suspended dust [Marczak 2017] with a particle diameter of up to $10 \mu \mathrm{m}$ (PM10) and up to $2.5 \mu \mathrm{m}$ (PM2.5). The test cycle consisted of 6 measuring days. On the day of measurements, test samples were collected in succession during classes with each group. Two measurements were taken in each group. The first measurement was carried out about 20 minutes after the beginning of the class. Until the first measurement was taken, didactic classes were conducted without using a chalk board. The interval between the first and second measurements was about 20 minutes. In the interval between measurements, chalk was used on a traditional metal plate and the board was often wiped with a sponge, often dry. Square, white, and small-dust chalk made by Mar-Bor company was used.

The measurements were made using a portable laser dust meter called DustTrak DRX Aerosol Monitor model 8533 (TSI Inc.). The dust meter is characterized by a short sampling time of the gas to be tested and allows the determination of mass concentration of particulate matter with particle sizes in the range of $0.1-15 \mu \mathrm{m}$. It can be powered by batteries or from the power socket. It measures the real-time dust concentration based on the laser light attenuation scattered on the test sample at an angle of 90 degrees.

The measuring point was located $1.2 \mathrm{~m}$ from the floor (breathing zone) and about $3 \mathrm{~m}$ from the chalk board (measured perpendicular to it). Before each measurement, the instrument was calibrated. A single measurement lasted 3 minutes. The flow rate of the air tested by the meter was $3 \mathrm{dm}^{3} / \mathrm{min}$. 
The results of the measurements are the average concentrations of the tested dust fractions for 30 seconds averaging time and maximum, minimum and average values recorded during the test. The result data were saved in the internal memory of the meter. For the time of averaging $30 \mathrm{sec}$ measurement results and the duration of the 3-minute test, six averaged values of dust fraction concentrations were stored in the meter's memory. On their basis, the average dust concentration from the measurement test was determined. The applied measurement method provides information on instantaneous concentrations of dust in the examined air.

\section{RESEARCH RESULTS}

The obtained results of mass concentration of total dust, PM10 and PM2.5 are presented in Table 1 . The set of results includes the minimum, maximum and average values of concentrations of total dust and PM10 fraction as well as average concentrations of PM2.5. The results of the average dust concentration measurements are illustrated in a graph (Figure 1).
Figure 1 shows that on the first and fifth day of measurement, measurements were taken in 2 laboratory groups taking classes one after another. On the second, fourth and sixth day of the measurement, two measurements were taken, because in each of these days only one group of students had educational classes. The third measurement session consisted of 6 measurements -2 measurements in each of the three laboratory groups.

In the assessment of the uncertainty (scatter) of the results of the measurement of the average concentration of dust, the uncertainty resulting from the use of measuring instruments (uncertainty of calibration) and random uncertainty were taken into account. The standard uncertainty was used as a quantitative measure of the uncertainty of the measurement results.

In calculating the uncertainty of measurement related to measuring instruments, the manufacturer's data with finite accuracy of measuring instruments is used. The accuracy of analog instruments is equal to the elementary space - the distance (in appropriate units) of two consecutive strokes on the scale of the instrument. In digital instruments, an elementary plot is equal to the unit of the smallest decade (unit of the de-

Table 1. Results of measurements of mass concentration of total dust, PM10 and PM2.5

\begin{tabular}{|c|c|c|c|c|c|c|c|c|c|}
\hline \multirow{2}{*}{$\begin{array}{l}\text { Measurement } \\
\text { session (day) }\end{array}$} & \multirow{2}{*}{$\begin{array}{l}\text { Lab. } \\
\text { group }\end{array}$} & \multirow{2}{*}{$\begin{array}{c}\text { Measurement } \\
\text { hour }\end{array}$} & \multicolumn{2}{|c|}{$\begin{array}{c}\text { Concentration } \min . \\
{\left[\mathrm{mg} / \mathrm{m}^{3}\right]}\end{array}$} & \multicolumn{2}{|c|}{$\begin{array}{c}\text { Concentration max. } \\
{\left[\mathrm{mg} / \mathrm{m}^{3}\right]}\end{array}$} & \multicolumn{3}{|c|}{$\begin{array}{c}\text { Average concentration (from } \\
\text { meter) } \\
{\left[\mathrm{mg} / \mathrm{m}^{3}\right]}\end{array}$} \\
\hline & & & $\begin{array}{l}\text { Total } \\
\text { dust } \\
\left(\mathrm{S}_{\min }\right) \\
\end{array}$ & $\begin{array}{c}\text { PM10 } \\
\left(\mathrm{S}_{\mathrm{PM} 10 \mathrm{~min}}\right)\end{array}$ & $\begin{array}{c}\text { Total } \\
\text { dust } \\
\left(\mathrm{S}_{\max }\right)\end{array}$ & $\begin{array}{c}\text { PM10 } \\
\left(\mathrm{S}_{\mathrm{PM} 10 \max }\right)\end{array}$ & $\begin{array}{l}\text { Total } \\
\text { dust } \\
\text { (S) }\end{array}$ & $\begin{array}{l}\mathrm{PM} 10 \\
\left(\mathrm{~S}_{\mathrm{PM} 10}\right)\end{array}$ & $\begin{array}{l}\mathrm{PM} 2.5 \\
\left(\mathrm{~S}_{\mathrm{PM} 2.5}\right)\end{array}$ \\
\hline \multirow{4}{*}{1} & \multirow{2}{*}{ G1 } & $12: 38$ & 0.083 & 0.037 & 0.103 & 0.04 & 0.094 & 0.039 & 0.028 \\
\hline & & 13:05 & 0.189 & 0.113 & 0.241 & 0.134 & 0.209 & 0.122 & 0.063 \\
\hline & \multirow{2}{*}{ G2 } & $15: 09$ & 0.024 & 0.018 & 0.043 & 0.022 & 0.032 & 0.02 & 0.016 \\
\hline & & $15: 31$ & 0.161 & 0.085 & 0.198 & 0.101 & 0.178 & 0.095 & 0.051 \\
\hline \multirow{2}{*}{2} & \multirow{2}{*}{ G3 } & $10: 45$ & 0.081 & 0.062 & 0.092 & 0.068 & 0.087 & 0.065 & 0.057 \\
\hline & & $11: 14$ & 0.178 & 0.116 & 0.2 & 0.129 & 0.189 & 0.121 & 0.085 \\
\hline \multirow{6}{*}{3} & \multirow{2}{*}{ G4 } & $10: 42$ & 0.148 & 0.136 & 0.168 & 0.141 & 0.157 & 0.139 & 0.132 \\
\hline & & 11:11 & 0.236 & 0.183 & 0.256 & 0.193 & 0.249 & 0.19 & 0.149 \\
\hline & \multirow{2}{*}{ G5 } & $12: 25$ & 0.165 & 0.140 & 0.171 & 0.145 & 0.168 & 0.142 & 0.131 \\
\hline & & $12: 49$ & 0.206 & 0.167 & 0.225 & 0.173 & 0.218 & 0.171 & 0.146 \\
\hline & \multirow{2}{*}{ G6 } & $14: 25$ & 0.147 & 0.131 & 0.17 & 0.137 & 0.159 & 0.134 & 0.125 \\
\hline & & $14: 50$ & 0.184 & 0.15 & 0.241 & 0.164 & 0.211 & 0.157 & 0.135 \\
\hline \multirow{2}{*}{4} & \multirow{2}{*}{ G7 } & $12: 50$ & 0.063 & 0.045 & 0.077 & 0.053 & 0.067 & 0.048 & 0.04 \\
\hline & & $13: 12$ & 0.127 & 0.086 & 0.179 & 0.104 & 0.152 & 0.094 & 0.063 \\
\hline \multirow{4}{*}{5} & \multirow{2}{*}{ G8 } & $10: 41$ & 0.047 & 0.037 & 0.099 & 0.045 & 0.073 & 0.037 & 0.025 \\
\hline & & $11: 04$ & 0.145 & 0.082 & 0.228 & 0.118 & 0.19 & 0.103 & 0.054 \\
\hline & \multirow{2}{*}{ G9 } & $12: 40$ & 0.034 & 0.021 & 0.054 & 0.029 & 0.042 & 0.024 & 0.017 \\
\hline & & 13:03 & 0.170 & 0.097 & 0.212 & 0.108 & 0.19 & 0.101 & 0.05 \\
\hline \multirow{2}{*}{6} & \multirow{2}{*}{ G10 } & $13: 40$ & 0.104 & 0.09 & 0.116 & 0.09 & 0.11 & 0.092 & 0.084 \\
\hline & & $13: 59$ & 0.159 & 0.126 & 0.22 & 0.15 & 0.185 & 0.136 & 0.104 \\
\hline
\end{tabular}




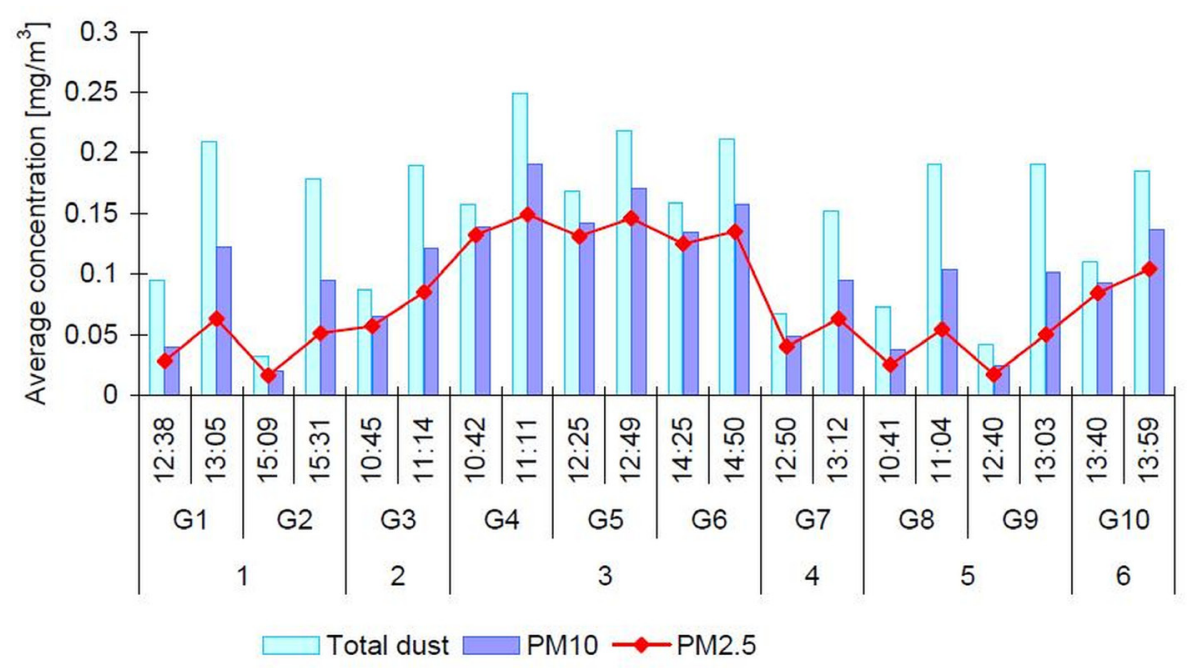

Fig. 1. Medium concentration of dust in the test cycle $(12: 38$ - measurement start time, G1, G2,..,G10 - laboratory groups, $1,2, \ldots, 6$ - day of measurements)

cade indicating the smallest measurement value). The dust meter used in the tests has, according to the manufacturer's data, a measuring range of $0.001-150 \mathrm{mg} / \mathrm{m}^{3}$. The elementary plot of the meter is $\Delta_{\mathrm{m}} \mathrm{S}=0.001 \mathrm{mg} / \mathrm{m}^{3}$. This means that the result of the dust concentration measurement carried out with this meter should not differ from the actual concentration value by more than one elementary scale. In other words, the deviation of the measurement result of the average dust concentration from the actual value can reach up to $\pm \Delta_{\mathrm{m}} \mathrm{S}$. This is border uncertainty. In order to convert it to standard uncertainty, it was assumed that the probability of obtaining any value of the total dust concentration in the range $\left(\mathrm{S}-\Delta_{\mathrm{m}} \mathrm{S} ; \mathrm{S}+\Delta_{\mathrm{m}} \mathrm{S}\right)$ is the same, i.e. it describes the homogeneous distribution (uniform). The standard deviation of the distribution of the homogeneous total dust concentration $(\mathrm{D}(\mathrm{S}))$, taking into account the adopted determinations, is determined by the formula:

$$
D(S)=\frac{\left(S+\Delta_{m} S\right)-\left(S-\Delta_{m} S\right)}{2 \sqrt{3}}=\frac{\Delta_{m} S}{\sqrt{3}}
$$

The standard uncertainty of the measurement of the total dust concentration resulting from the uncertainty of the calibration $\left(\mathrm{u}_{\mathrm{m}}(\mathrm{S})\right)$, equal to the standard deviation of the homogeneous probability distribution, describes the dependence:

$$
u_{m}(S)=\frac{\Delta_{m} S}{\sqrt{3}}
$$

The random uncertainty of the measured value of mean total dust concentration is caused by the instability of external conditions during measurements and the specificity of phenomena occurring in the measuring chamber of the instrument. It is illustrated by the spread of dust concentration results for subsequent averaging times. Random uncertainty $\left(\Delta_{\mathrm{p}} \mathrm{S}\right)$ for each measurement was calculated according to the relationship:

$$
\Delta_{p} S=S_{\max }-S_{\min }
$$

where: $S_{\min }$ - the minimum concentration of total dust in the test

$S_{\max }-$ maximum concentration of total dust in the test.

The change of random uncertainty $\Delta_{\mathrm{p}} \mathrm{S}$ into standard uncertainty was done in the same way as for the uncertainty of calibration. As a result, the standard uncertainty of measuring the average dust concentration resulting from the uncertainty of random measurement $\left(u_{p}(S)\right)$ will be equal:

$$
u_{p}(S)=\frac{\Delta_{p} S}{\sqrt{3}}
$$

The standard integer uncertainty was calculated using the following variance property for the independent variables $\mathrm{X}$ and $\mathrm{Y}$ :

$$
D^{2}(X+Y)=D^{2}(X)+D^{2}(Y)
$$

Standard deviation will be equal to:

$$
D(X+Y)=\sqrt{D^{2}(X)+D^{2}(Y)}
$$

The uncertainty of the standard total measurement of the mean concentration of total dust is expressed by the following relationship: 


$$
u(S)=\sqrt{\left[u_{m}(S)\right]^{2}+\left[u_{p}(S)\right]^{2}}
$$

where: $u(S)$ - total standard uncertainty.

Standard uncertainty values and total standard uncertainty of average dust concentration measurements are presented in Table 2 .

By analogy, the uncertainty of measurements of the average concentration of PM10 was determined, i.e. $u_{m}\left(S_{P_{10} 10}\right)$ - measurement uncertainty calculated on the basis of the accuracy of the measuring instrument, $\mathrm{u}_{\mathrm{p}}\left(\mathrm{S}_{\mathrm{PM} 10}\right)$ - uncertainty resulting from the statistical distribution of PM10, $\mathrm{u}\left(\mathrm{S}_{\mathrm{PM} 10}\right)$ - uncertainty with the standard total measurement dust concentration of PM10.

The standard uncertainty values and the total standard uncertainty of measurements of the average concentration of PM10 fraction are given in Table 3.

It was observed that the total standard uncertainty shows higher values for the second measurement in each of the G1-G10 groups as compared to the first measurement (Tables 2 and 3). This is due to the larger scatter of instantaneous dust concentration values during the second measurement than during the first measurement.

Before the first measurement, the dustiness in the room was small, although different in in- dividual measuring tests. These differences were caused by a different proportion of secondary pollination in air pollution. Secondary emission consists in raising dust which was previously settled on solid surfaces. Increased activity of students during the course of classes, with simultaneous occurrence of layers of settled dust, increases the concentration of dust in the room. On the third day of the measurements, during the studies in the G4-G6 groups, significantly higher values of total dust concentration were measured in the first measurement compared to the G1, G2 and G7G10 tests. At the same time, it was found that the results of the first measurement of mean total dust concentration in the G4-G6 trials were similar to each other and were respectively $0.157 \mathrm{mg} / \mathrm{m}^{3}$, $0.168 \mathrm{mg} / \mathrm{m}^{3}$ and $0.159 \mathrm{mg} / \mathrm{m}^{3}$. In the research trials G1, G2, G7-G10, the values of mean total dust concentration ranged from $0.032 \mathrm{mg} / \mathrm{m}^{3}$ (G2) to $0.11 \mathrm{mg} / \mathrm{m}^{3}$ (G10). Based on the observations, it can be concluded that the increase in the dust concentration in the first measurement in the G4-G6 trials (3rd day of measurement) was the result of irritating dust settled in the room. This was favored by the increased activity of students in G4-G6 groups in preparation for conducting research as a part of didactic classes.

Table 2. Values of uncertainty of measurements of mean mass concentration of total dust

\begin{tabular}{|c|c|c|c|c|c|c|}
\hline $\begin{array}{l}\text { Measurement } \\
\text { session (day) }\end{array}$ & $\begin{array}{l}\text { Lab. } \\
\text { group }\end{array}$ & Measurement hour & $\begin{array}{c}\text { Standard } \\
\text { uncertainty } \\
u_{\mathrm{m}}(\mathrm{S}) \\
{\left[\mathrm{mg} / \mathrm{m}^{3}\right]}\end{array}$ & $\begin{array}{c}\text { Random } \\
\text { uncertainty } \\
u_{p}(\mathrm{~S}) \\
{\left[\mathrm{mg}^{3} \mathrm{~m}^{3}\right]}\end{array}$ & $\begin{array}{c}\text { Total uncertainty } \\
\mathrm{u}(\mathrm{S}) \\
{\left[\mathrm{mg} / \mathrm{m}^{3}\right]}\end{array}$ & $\begin{array}{c}\text { Measurement } \\
\text { result } \\
\mathrm{S} \\
{\left[\mathrm{mg} / \mathrm{m}^{3}\right]}\end{array}$ \\
\hline \multirow{4}{*}{1} & \multirow{2}{*}{ G1 } & $12: 38$ & 0.00058 & 0.01155 & 0.012 & $0.094(0.012)$ \\
\hline & & 13:05 & 0.00058 & 0.03002 & 0.030 & $0.209(0.03)$ \\
\hline & \multirow{2}{*}{ G2 } & $15: 09$ & 0.00058 & 0.01097 & 0.011 & $0.032(0.011)$ \\
\hline & & $15: 31$ & 0.00058 & 0.02136 & 0.021 & $0.178(0.021)$ \\
\hline \multirow{2}{*}{2} & \multirow{2}{*}{ G3 } & $10: 45$ & 0.00058 & 0.00635 & 0.006 & $0.087(0.006)$ \\
\hline & & $11: 14$ & 0.00058 & 0.01270 & 0.013 & $0.189(0.013)$ \\
\hline \multirow{6}{*}{3} & \multirow{2}{*}{ G4 } & $10: 42$ & 0.00058 & 0.01155 & 0.012 & $0.157(0.002)$ \\
\hline & & $11: 11$ & 0.00058 & 0.01155 & 0.012 & $0.249(0.012)$ \\
\hline & \multirow{2}{*}{ G5 } & $12: 25$ & 0.00058 & 0.00346 & 0.004 & $0.168(0.004)$ \\
\hline & & $12: 49$ & 0.00058 & 0.01097 & 0.011 & $0.218(0.011)$ \\
\hline & \multirow{2}{*}{ G6 } & $14: 25$ & 0.00058 & 0.01328 & 0.013 & $0.159(0.013)$ \\
\hline & & $14: 50$ & 0.00058 & 0.03291 & 0.033 & $0.211(0.033)$ \\
\hline \multirow{2}{*}{4} & \multirow{2}{*}{ G7 } & $12: 50$ & 0.00058 & 0.00808 & 0.008 & $0.067(0.008)$ \\
\hline & & $13: 12$ & 0.00058 & 0.03002 & 0.030 & $0.152(0.03)$ \\
\hline \multirow{4}{*}{5} & \multirow{2}{*}{ G8 } & $10: 41$ & 0.00058 & 0.03002 & 0.030 & $0.073(0.03)$ \\
\hline & & 11:04 & 0.00058 & 0.04792 & 0.048 & $0.19(0.048)$ \\
\hline & \multirow{2}{*}{ G9 } & $12: 40$ & 0.00058 & 0.01155 & 0.012 & $0.042(0.012)$ \\
\hline & & $13: 03$ & 0.00058 & 0.02425 & 0.024 & $0.19(0.024)$ \\
\hline \multirow{2}{*}{6} & \multirow{2}{*}{ G10 } & $13: 40$ & 0.00058 & 0.00693 & 0.007 & $0.11(0.007)$ \\
\hline & & $13: 59$ & 0.00058 & 0.03522 & 0.035 & $0.185(0.035)$ \\
\hline
\end{tabular}


Table 3. Values of uncertainty of measurements of average mass concentration of PM10 dust

\begin{tabular}{|c|c|c|c|c|c|c|}
\hline $\begin{array}{l}\text { Measurement } \\
\text { session (day) }\end{array}$ & $\begin{array}{l}\text { Lab. } \\
\text { group }\end{array}$ & Measurement hour & $\begin{array}{c}\text { Standard } \\
\text { uncertainty } \\
u_{\mathrm{m}}(\mathrm{S}) \\
{\left[\mathrm{mg} / \mathrm{m}^{3}\right]}\end{array}$ & $\begin{array}{c}\text { Random } \\
\text { uncertainty } \\
u_{\mathrm{p}}(\mathrm{S}) \\
{\left[\mathrm{mg}^{3} \mathrm{~m}^{3}\right]}\end{array}$ & \begin{tabular}{|c} 
Total uncertainty \\
$\mathrm{u}(\mathrm{S})$ \\
{$\left[\mathrm{mg} / \mathrm{m}^{3}\right]$}
\end{tabular} & $\begin{array}{c}\text { Measurement } \\
\text { result } \\
\mathrm{S} \\
{\left[\mathrm{mg} / \mathrm{m}^{3}\right]}\end{array}$ \\
\hline \multirow{4}{*}{1} & \multirow{2}{*}{ G1 } & $12: 38$ & 0.00058 & 0.00173 & 0.002 & $0.039(0.002)$ \\
\hline & & 13:05 & 0.00058 & 0.01212 & 0.012 & $0.122(0.012)$ \\
\hline & \multirow{2}{*}{ G2 } & $15: 09$ & 0.00058 & 0.00231 & 0.002 & $0.02(0.002)$ \\
\hline & & $15: 31$ & 0.00058 & 0.00924 & 0.009 & $0.095(0.009)$ \\
\hline \multirow{2}{*}{2} & \multirow{2}{*}{ G3 } & $10: 45$ & 0.00058 & 0.00346 & 0.004 & $0.065(0.004)$ \\
\hline & & $11: 14$ & 0.00058 & 0.00751 & 0.008 & $0.121(0.008)$ \\
\hline \multirow{6}{*}{3} & \multirow{2}{*}{ G4 } & $10: 42$ & 0.00058 & 0.00289 & 0.003 & $0.139(0.003)$ \\
\hline & & $11: 11$ & 0.00058 & 0.00577 & 0.006 & $0.19(0.006)$ \\
\hline & \multirow{2}{*}{ G5 } & $12: 25$ & 0.00058 & 0.00289 & 0.003 & $0.142(0.003)$ \\
\hline & & $12: 49$ & 0.00058 & 0.00346 & 0.004 & $0.171(0.004)$ \\
\hline & \multirow{2}{*}{ G6 } & $14: 25$ & 0.00058 & 0.00346 & 0.004 & $0.134(0.004)$ \\
\hline & & $14: 50$ & 0.00058 & 0.00808 & 0.008 & $0.157(0.008)$ \\
\hline \multirow{2}{*}{4} & \multirow{2}{*}{ G7 } & $12: 50$ & 0.00058 & 0.00462 & 0.005 & $0.048(0.005)$ \\
\hline & & $13: 12$ & 0.00058 & 0.01039 & 0.01 & $0.094(0.01)$ \\
\hline \multirow{4}{*}{5} & \multirow{2}{*}{ G8 } & $10: 41$ & 0.00058 & 0.00462 & 0.005 & $0.037(0.005)$ \\
\hline & & 11:04 & 0.00058 & 0.02078 & 0.021 & $0.103(0.021)$ \\
\hline & \multirow{2}{*}{ G9 } & $12: 40$ & 0.00058 & 0.00462 & 0.005 & $0.024(0.005)$ \\
\hline & & $13: 03$ & 0.00058 & 0.00635 & 0.006 & $0.101(0.006)$ \\
\hline \multirow{2}{*}{6} & \multirow{2}{*}{ G10 } & $13: 40$ & 0.00058 & 0.0 & 0.001 & $0.092(0.001)$ \\
\hline & & $13: 59$ & 0.00058 & 0.01386 & 0.014 & $0.136(0.014)$ \\
\hline
\end{tabular}

A sudden change in environmental conditions in the room - an increase in the content of dust - occurred as a result of writing with chalk and wiping it with a dry sponge of chalk dust from the board. The values of the mass concentration of total dust in the second measurement in the G2 group were higher even by $456.25 \%$ from the concentration value in the first measurement (Table 2). The high increase in the total dust concentration in the internal air as a result of chalk dust emission was also recorded during the tests on the fifth day of measurement in the G9 group - about $352 \%$ higher than in the first measurement. The smallest impact of chalk dust emission on indoor air quality was found during G5 and G6 measurement tests, in which the concentration of total dust in the second measurement was higher by approx. $30 \%$ and approx. $32 \%$ respectively than in the first measurement.

The tests showed that the share of the average PM10 fraction in the total dust was from about $41.5 \%$ (G1, first measurement) to about $88.5 \%$ (G4, first measurement). The PM2.5 fraction constituted from $49.5 \%$ (G9, second measurement) to $94.96 \%$ (G4, first measurement) of the PM10 dust fraction. A larger share of the average PM2.5 dust concentration in the PM10 dust was observed in the first measurement than in the second measure- ment in each of the G1-G10 groups. It follows that the dust in the internal air was enriched with PM2.5 fraction before the appearance of the chalk dust source (Figure 2).

On the basis of the presented test results, it can be seen that in each second measurement of test samples G1 to G10 the values of total dust, PM10 and PM2.5 concentrations were higher than in the first measurement. The immediate cause of the increase in the dust content in the indoor air in the didactic room was chalk dust, which arises when writing with a chalk and wiping it with a sponge.

\section{CONCLUSIONS}

Before assessing the values of dust concentrations in the indoor air, the measurement results should be compared with the applicable permissible standards or other available data.

The applicable regulations in Poland [Announcement Dz.U. 2017, poz. 1348] determine the values of the highest permissible concentrations of harmful dust agents at work stations. For dust categories: other non-toxic industrial dusts, including those containing free (crystalline) silica below $2 \%$, the maximum permissible concentration of total dust is $10 \mathrm{mg} / \mathrm{m}^{3}$. Taking into account 


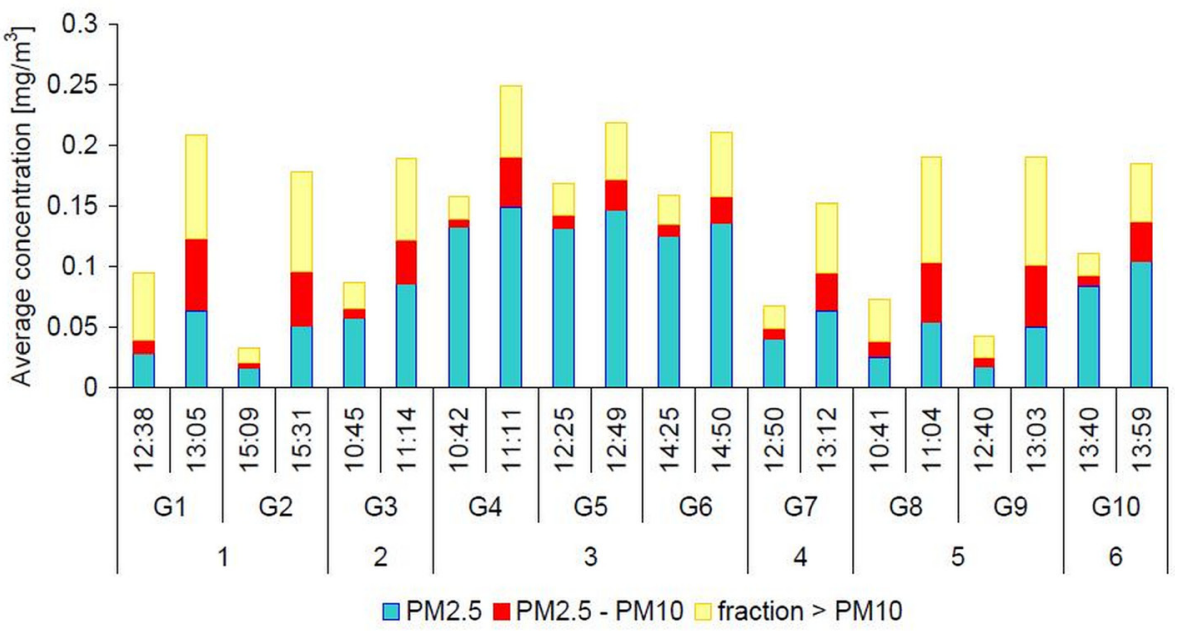

Fig. 2. The average concentration of PM2.5, PM2.5-PM10 and above PM10 dust fraction in the total mean concentration of dust $(12: 38$ - measurement time start, G1, G2,..,G10 - laboratory groups, 1, 2,...,6 - day measurements)

the results of measurements, it can be concluded that the total dust concentration in the tested room does not exceed the given limit. In addition to work positions, there are no legal regulations regarding internal air quality standards.

In EU and Polish law, however, there are acceptable standards for particulate matter PM10 and PM2.5 in the external air [Regulation Dz.U. 2012, poz.1031].

The permissible level for average daily concentrations of PM10 dust is $50 \mu \mathrm{g} / \mathrm{m}^{3}$, and for annual concentrations of $40 \mu \mathrm{g} / \mathrm{m}^{3}$. For PM2.5, the norm is defined only for mean values of annual concentrations - it is $25 \mu \mathrm{g} / \mathrm{m}^{3}$. According to World Health Organization (WHO) recommendations [2006], the daily PM2.5 dust concentration should not exceed $25 \mu \mathrm{g} / \mathrm{m}^{3}$ and annual $10 \mu \mathrm{g} / \mathrm{m}^{3}$. Referring to these standards, it can be said that for 20 measurements of PM2.5, 17 concentrations exceeded the permissible level of $25 \mu \mathrm{g} / \mathrm{m}^{3}$. Analyzing the values of PM10, dust concentrations obtained from measurements, it can be noticed that in 15 measuring samples they were much higher than $50 \mu \mathrm{g} / \mathrm{m}^{3}$.

Research shows that the quality of indoor air in the teaching room is affected by the quality of outdoor air, as well as the source of dust emission in the room. These sources include chalk dust emitted during the use of chalk and the abrasion of chalk dust from the board, as well as dust settled by air movement.

Average concentrations of total dust varied from $0.152-0.294 \mathrm{mg} / \mathrm{m}^{3}$ with the occurrence of chalk dust emission, while before emission they ranged from $0.042-0.157 \mathrm{mg} / \mathrm{m}^{3}$. The research also confirmed an increase in the concentration of PM10 and PM2.5 fractions caused by the chalk dust emission source - for PM10 fractions from values in the $0.02-0.142 \mathrm{mg} / \mathrm{m}^{3}$ range before dust emission to values from $0.094-0.19 \mathrm{mg} / \mathrm{m}^{3}$ after emission.

For better results, the scope of tests should be extended to include measurements in the conditions of each table wiping with a damp sponge and using the so-called dust-free chalk. In order to assess the inhalation of chalk dust of people writing on the blackboard, it is advisable to measure air samples taken from the breathing zone of these people. Research is also needed to determine the effect of dust concentration, especially the respirable fraction, on the respiratory system of people who stay indoors for a long time with poor air quality. Future tests should extend the duration of the measurement tests and the research cycle to obtain large data sets.

As a result of the research, factors influencing the increase of dust concentration in the indoor air were identified. It allows to indicate actions limiting or eliminating the sources of these factors. These activities include the permanent use of a damp sponge to wipe the traditional board, ensure proper ventilation in the room, or replace traditional chalk boards with dry-wipe magnetic.

\section{REFERENCES}

1. Bochentyn B., Kusz B. 2014. Methodology of measurements and uncertainty and measurement errors (in Polish). LAB Laboratoria, Aparatura, Badania, R. 19, 5, 26-35. 
2. Gajdek M. 2012. Analysis of measurement results: Methods for estimating measurement uncertainty (in Polish). Politechnika Świętokrzyska, Kielce.

3. Jakubowski J. Health effects of exposure to industrial dust in the work environment (in Polish). http://docplayer.pl/6646363-Zdrowotne-skutkinarazenia-na-pyl-przemyslowy-w-srodowiskupracy.html (access on 11.02.2018).

4. Marczak H. 2017. Particulate matter in atmospheric air in urban agglomeration. Journal of Ecological Engineering, 18(3), 149-155.

5. Announcement of the Minister of Family, Labor and Social Policy of 7 June 2017 on the publication of a uniform text of the Regulation of the Minister of Labor and Social Policy on the highest permissible concentrations and intensities of factors harm- ful to health in the work environment (in Polish). Dz.U. 2017, poz. 1348.

6. Olszewski A. 1998. Selected parameters of the microstructure of writing chalk and rocks marl (in Polish). Przegląd Geologiczny, vol. 46, 9, 845-850.

7. PN-ISO 4225:1999. Air quality. General issues. Terminology (in Polish).

8. PN-ISO 7708:2001. Air quality. Definitions of the dust fraction used in the collection of samples for health risk assessment (in Polish).

9. Regulation of the Minister of the Environment of 24 August 2012 on the levels of certain substances in the air (in Polish). Dz.U. 2012, poz.1031.

10. WHO 2006. Air quality guidelines for particulate matter, ozone, nitrogen dioxide and sulfur dioxide. Global Update 2005. Geneva. 